\title{
What is Green Manufacturing? A Quantitative Literature Review
}

\author{
Ira Setyaningsih ${ }^{1,2,}$, Wakhid Slamet Ciptono ${ }^{2}$, Nurul Indarti $^{2}$, and Nofie Iman Vidya Kemal ${ }^{2}$ \\ ${ }^{1}$ UIN SUnan Kalijaga, Industrial Engineering Department, Yogyakarta, Indonesia \\ ${ }^{2}$ Universitas Gadjah Mada, Management Department, Yogyakarta, Indonesia
}

\begin{abstract}
This paper is a decade This paper is a decade of literature review (2009-2019), about green manufacturing (GM) topic. Quantitative methods with the Publish or Perish (PoP) and VOSviewer software are used to filter the appropriate papers. The database used in PoP is Google Scholar and Scopus. During this time 403 articles were included in PoP screening, 212 articles on the Google Scholar database and 191 articles on the Scopus database. Paper not Q1 and Q2, duplicate paper in both databases, paper not in English, book review, were excluded from the analysis. The results obtained 78 papers that can be analyzed. This paper elaborate network analysis of research in green manufacturing topic and describe in detail the publications in the GM field, including journals and the year of publication. We find that there are three journals dominated the publication in this topic, Journal of Cleaner Production, International Journal of Precision Engineering and Manufacturing, and International Journal of Production Research. In this decade, GM was discussed extensively in 2018. From VosViewer software, we get four main research clusters, that is, model, green manufacturing, industry and practice. There are many topics dealing with GM can be developed in future research from maps shown by VosViewers, such as adoption, GSCM, and environmental regulation.
\end{abstract}

\section{Introduction}

The topic of GM emerged in the early 1990s, and was driven by human concerns about the environment [1]. Initially, GM's focus was only on process-oriented, reducing waste in the production process. This focus then develops into product-oriented, reducing resources, polluting material, and energy [1]. Green manufacturing (GM) has a variety of word similar, such as cleaner production or green practices [2]. This topic growth rapidly in this last decade. The term of green become an important and interesting topic discussion for several reason, such as the increasing of pollution and waste, the limitation and decreasing of natural resources, and global warming effect [3].

This study have several purpose, to provide an extensive literature review on green manufacturing, specifically:

- clarify the concept of GM

- overview the existing body of literature

- explore the trend in the GM research and suggest a future research topic

Some authors have their own definitions about GM. GM interpreted as paradigm, process, system or method. Despite having different explanations, the researchers agreed that GM essentially minimizes resources and reduces waste to protect the environment (Table 1.).
This paper is organized into five sections. The first section discusses GM in general and explains the purpose of the paper. In Section 2, the existing review of 'green manufacturing' definition are described. We clarify the definition of GM in this section. In Section 3 we presented the steps of the method and methodology used to conduct the literature review. The results of VOSviewer software is discusses in Section 4. Conclusions, and future research suggestion are appear in Section 5.

\section{Literature Review}

The literature review research on GM was examined by Rehman and Shrivastava in 2013 in sufficient detail [1]. They concluded that research on GM was classified into 12 branches, namely green design, design for environment, green technologies, life cycle assessment, green process planning, green supply chain, reverselogistic, green purchasing/marketing, green organization culture, green regulation, green productivity, green economics, and green disposal. Their paper concludes that GM includes a comprehensive set of processes in all activities in business that have an impact on the environment. Research in past, present and probably future have same direction but different focus. In the past, researchers highlighted industrial behavior that paid more attention to the final process, 'end of pipe' process, how to reduce waste or pollution. At present,

Corresponding author: ira_darusalam@yahoo.com 
researchers assess that the company's focus shifts to the 'pressure' of government or the environment to adopt GMs. Whereas in the future, it is estimated that research will focus on the life cycle and product design that are still a little highlighted [1].

Green manufacturing has been explained by various authors. Sangwan and Mittal's article on bibliometric GMs and similar frameworks found that there are eight frameworks that have been used interchangeably by researchers, for example cleaner production, sustainable production, sustainable manufacturing [2]. Dornfeld [4] defined green manufacturing as a process or system to promote sustainability and to reduce the environmental impact by minimizing resources and decreasing pollution by recycling or developing green products. Deif [5] explained that GM reflects a new manufacturing paradigm that integrate various green strategies, drivers and techniques to become more eco-efficient, including reducing material and energy, substituting input materials and recycling. Shrivastava and Shrivastava [6] noted that GM is a method for manufacturing that minimizes waste and pollution, inhibits the rate of use of natural resources and reducing input material, and reusing components, to help to build products more efficiently. Chuang and Yang [7] analyze some literature and concluded that GM concluding GM as a manufacturing method, the process of transforming materials or parts into finished goods and fulfill customer expectations that minimises waste and pollution [7]. We resume the definition by some authors in Table 1 and conclude our own definitions in Fig 1.

Table 1. GM definitions by various authors

\begin{tabular}{|l|l|l|l|l|l|l|l|}
\hline Author & $\begin{array}{l}\text { GM } \\
\text { define }\end{array}$ & $\mathbf{1}$ & $\mathbf{2}$ & $\mathbf{3}$ & $\mathbf{4}$ & $\mathbf{5}$ & $\mathbf{6}$ \\
\hline Dornfeld [4] & $\begin{array}{l}\text { Process; } \\
\text { System }\end{array}$ & v & v & v & v & v & \\
\hline Deif [5] & Paradigm & v & v & & v & & v \\
\hline $\begin{array}{l}\text { Shrivastava and } \\
\text { Shrivastava [6] }\end{array}$ & Method & & v & v & v & & v \\
\hline $\begin{array}{l}\text { Chuang and } \\
\text { Yuang [7] }\end{array}$ & Method & & & v & & & v \\
\hline
\end{tabular}

(1) Reduce environmental impact; (2) minimizing resources; (3) minimizing pollution; (4) recycling; (5) green products; (6) efficiently goal.

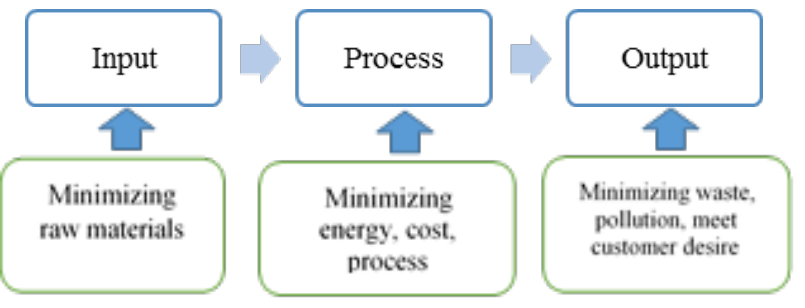

Fig. 1. GM define.

We conclude in this paper that GM is a manufacturing method with minimizing natural resources as input; process within minimal energy and cost; and produce finished goods in minimizing waste and pollution as output, but still meet customer desire (Fig. 1.).

\section{Methodology}

Data was collected from the Google Scholar (GS) database and Scopus database by Publish or Perish (PoP) software from Harzing [8] in Februari 2019. We used the search strings "green manufacturing" only to narrow the findings. Through this step, we get 212 papers from Scopus and 191 papers from GS. The total number in the initial search phase is 403 papers. In the next step we select and use paper from top journal (Q1 and Q2) only, based on scimago website.

Figure 2 shows many journals not analyzed. Various reasons for not analyzing this paper are presented in Table 2. Initially, we examined the paper from Scopus, this led to the Google Sholar database, 98 papers categorized as duplicated. This results in the final result, the data on google scholar seems to be only a few (four) classified into Q1 and Q2. Actually, many journals are identified in the GS database as Q1 and Q2.

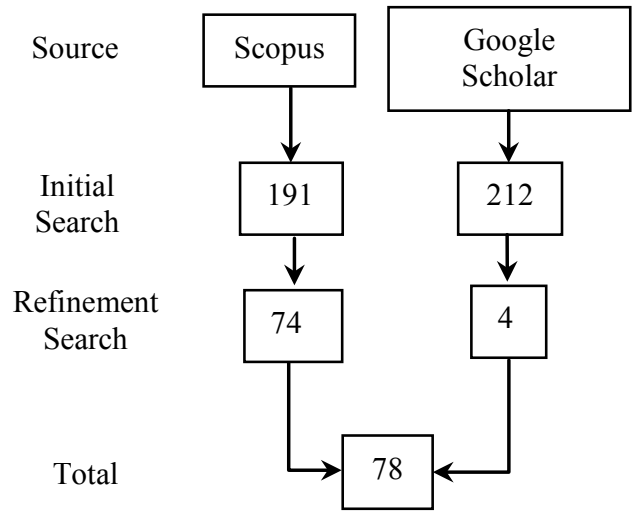

Fig. 2. Overview of paper selection process.

Figure 2 shows many journals not analyzed. Various reasons for not analyzing this paper are presented in Table 2.

Table 2. Database searching.

\begin{tabular}{|l|l|l|}
\hline & Scopus & Google Scholar \\
\hline Initial & 191 & 212 \\
\hline No Article/Book Review & 3 & 1 \\
\hline Not in Business/Management & 37 & 5 \\
\hline Not in Scimago & 12 & 89 \\
\hline Q3/Q4 & 65 & 14 \\
\hline Non English & 0 & 1 \\
\hline Duplicate & 0 & 98 \\
\hline Final Result & $\mathbf{7 4}$ & $\mathbf{4}$ \\
\hline
\end{tabular}

The highest number is paper that is not in Scimago as many as 101, followed by database duplication from Scopus and GS is 98 papers. Q3 and Q4 79 papers, and 42 papers not in business/management topic, such as green tea and green ceramics. The latest data not included in the analysis are two articles in the form of book reviews and two articles we can not obtained. Distribution of data from 2009 to 2019 from two databases, Scopus and GS, as complete as can be seen in Table 3. 
Table 3. Data distribution per year.

\begin{tabular}{|l|l|l|}
\hline & Scopus & GS \\
\hline 2009 & 7 & 12 \\
\hline 2010 & 6 & 9 \\
\hline 2011 & 9 & 13 \\
\hline 2012 & 17 & 15 \\
\hline 2013 & 13 & 21 \\
\hline 2014 & 17 & 26 \\
\hline 2015 & 25 & 29 \\
\hline 2016 & 29 & 28 \\
\hline 2017 & 26 & 18 \\
\hline 2018 & 40 & 37 \\
\hline 2019 & 2 & 4 \\
\hline Amount & $\mathbf{1 9 1}$ & $\mathbf{2 1 2}$ \\
\hline & & \\
\hline
\end{tabular}

Table 4. Difference of searching metric.

\begin{tabular}{|l|l|l|}
\hline & Initial & Refinement \\
\hline Papers & 323 & 78 \\
\hline Citations & 2479 & 1558 \\
\hline Years & 10 & 10 \\
\hline Cites_Year & 247,9 & 155,8 \\
\hline Cites_Paper & 7,67 & 19,97 \\
\hline Cites_Author & 2172,3 & 1466,95 \\
\hline Papers_Author & 236,17 & 68,79 \\
\hline Authors_Paper & 1,81 & 1,38 \\
\hline h_index & 24 & 20 \\
\hline Cites_Author_Year & 217,23 & 146,69 \\
\hline Year_first & 2009 & 2009 \\
\hline Year_last & 2019 & 2019 \\
\hline
\end{tabular}

Data obtained from PoP software shows that there is no significant difference between Scopus and GS. From both databases, the initial and refinement metric data are obtained (Table 4). Initial metric data is data before being analyzed. In the initial data, shows the number of paper is 323 , it because both databases have been merged, and the system eliminates the paper that he knows has the same data information.

Table 4 shows that the papers in Q1 and Q2 have a large impact, as seen from the increased data in citation paper, from 7.67 to 19.97 .

\section{Discussion}

PoP software helps researcher to gain the appropriate journals. We analyze 78 journals, that spread from 2009 to February 2019. Fig 3 shows in 2018 research about GM are highest, and the lowest are in 2009.

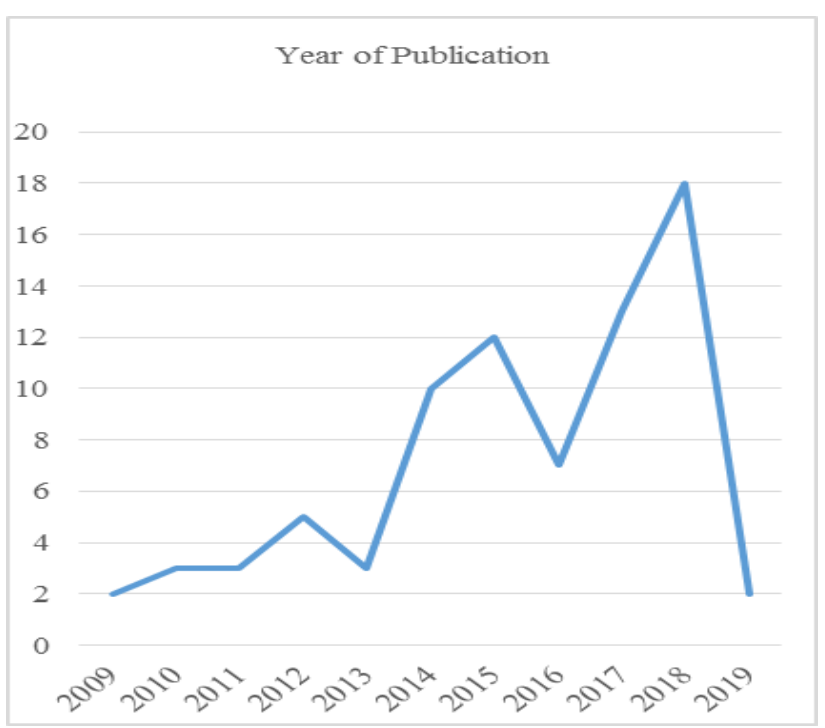

Fig. 3. Year of publication.

Figure 3 shows that in general there is an increase in research in the realm of GM topics. The decline in research occurred in 2016 and 2013. After 2016, this trend increased significantly. this means that this topic is becoming a concern in society and researchers.

The most popular Journal Publication that published this topic is Journal Cleaner Production (Table 5). This is consistent with previous research, bibliometric analysis with Google Scholar data sources only [9]. Other journals that contribute one article each and not listed in the Table 5 are International Journal of Green Economics, B.E. Journal of Economic Analysis and Policy, European Journal of Operational Research, European Journal of Wood and Wood Products, Indian Journal of Science and Technology, International Journal of Advanced Manufacturing Technology, International Journal of Business Innovation and Research, International Journal of Computer Integrated Manufacturing, International Journal of Economic Research, International Journal of Logistics Systems and Management, International Journal of Quality and Reliability Management, Journal of Environment and Development, Journal of Environmental Management, Journal of Environmental Planning and Management, Journal of Industrial Ecology, Journal of Manufacturing Systems, Journal of Remanufacturing, Journal of the Society for Information Display, World Applied Sciences, International Journal of Sustainable Development \& World Ecology, International Journal of Industrial and Systems Engineering.

Table 5. Journals publication

\begin{tabular}{|l|l|}
\hline Journal & Amount \\
\hline Journal of Cleaner Production & 19 \\
\hline $\begin{array}{l}\text { International Journal of Precision Engineering and } \\
\text { Manufacturing }\end{array}$ & 8 \\
\hline International Journal of Production Research & 8 \\
\hline Journal of Manufacturing Technology Management & 5 \\
\hline Benchmarking: An International Journal & 4 \\
\hline International Journal of Production Economics & 4 \\
\hline $\begin{array}{l}\text { International Journal of Productivity and Quality } \\
\text { Management }\end{array}$ & 2 \\
\hline International Journal of Procurement Management & 2 \\
\hline International Journal of Energy Economics and & 2 \\
\hline
\end{tabular}




\begin{tabular}{|l|l|}
\hline Policy & \\
\hline $\begin{array}{l}\text { International Journal of Environmental Research } \\
\text { and Public Health }\end{array}$ & 2 \\
\hline $\begin{array}{l}\text { International Journal of Logistics Research and } \\
\text { Applications }\end{array}$ & 2 \\
\hline Others & 20 \\
\hline Total & $\mathbf{7 8}$ \\
\hline
\end{tabular}

Vosviewer software that was created and explained by Van Eck and Waltman [10] was used to analyze the final data, to see the distribution of data patterns. VOSviewer shows, there are 2342 terms words that appear more than once in the title and abstract. Then the vosviewer analyzes the words, which appear above 10 times, in the 78 titles and abstracts of the papers and found 48 threshold. If we want more rigid results, we can change this amount. We can replace it with a larger number, 15 or 20 times.

Figure 4 shows density visualisation mapping from VOSViewer. The red colors presentes the largest number of items and the highest weights of elements, followed by yellow and green ones. The red colors means that these words, such as 'practice', 'model', 'process', 'performance', ' industry' are widely used by researchers. Our consideration is in the words inside green colours, such as 'energy', and 'environmental regulation'. In the middle between red and green colours, is yellow colours. The words such as 'adoption', 'survey', 'gscm', 'smes', 'cost', gives researchers an opportunity to be further investigated. Researchers can conduct future research on research topics based on these words inside green and yellow colour of density visualisation mapping.

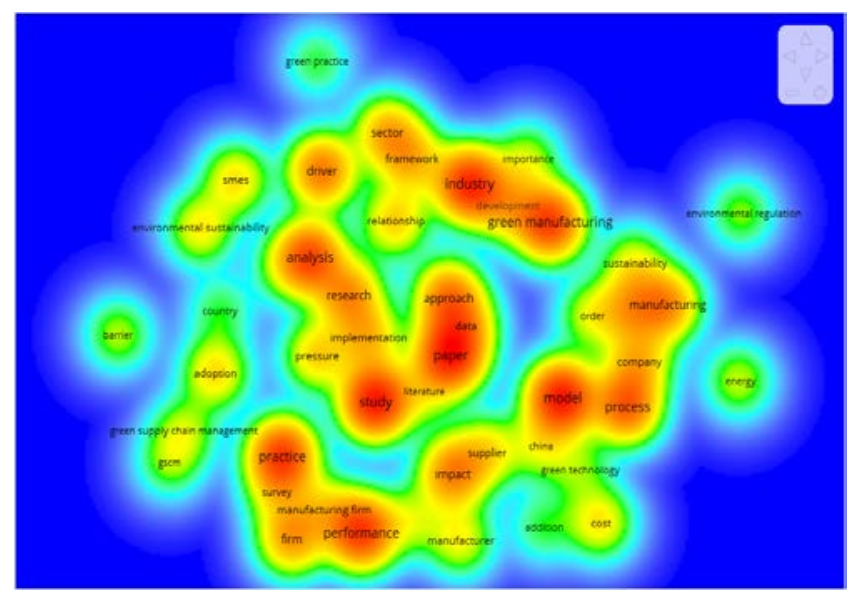

Fig. 4. Density visualisation mapping.

\section{Conclusion}

GM become an interesting topic discussed in line with the increasing public awareness of the importance of being friendly to the environment. People in the world are beginning to realize that the environment has limited resources and are starting to worry about its availability, such as reduced water supply and depleting supply of energy sources. The industry also began to notice about this environment issue, one of the approaches taken through adoption of GM.

GM, basically is a process of innovation from traditional manufacturing. GMs pay attention to environmental aspects in all manufacturing activities, such as inputs, processes and outputs.
In future research, there are still many opportunity to conduct research topic in GM related to adoption, SMES, GSCM, energy and environmental regulation.

Mrs. Ira Setyaningsih gratefully acknowledge to Indonesia Endowment Fund for Education (LPDP) for their support on her study and this research.

\section{References}

[1] Rehman, M. and Shrivastava, R. L. 2013. Green Manufacturing (GM): Past, Present and future (A State of Art Review). World Rev. Sci. Technol. Sustain. Dev. 10, 1/2/3, 17-55.

[2] Sangwan, K. S. and Mittal, V. K. 2015. A bibliometric analysis of green manufacturing and similar frameworks. Manag. Environ. Qual. An Int. J. 26, 4, 566-587.

[3] Mittal, V. K. and Sangwan, K. S. 2014. Prioritizing barriers to green manufacturing: Environmental, social and economic perspectives. Procedia CIRP. 17, 559-564.

[4] Dornfeld, D., Yuan, C., Diaz, N., Zhang, T., and Vijayaraghavan, A. 2013. Introduction to Green Manufacturing.

[5] Deif, A. M. 2011. A system model for green manufacturing. J. Clean. Prod. 19, 14, 1553-1559.

[6] Shrivastava, S. and Shrivastava, R. L. 2017. A systematic literature review on green manufacturing concepts in cement industries. Int. J. Qual. Reliab. Manag. 34, 1, 6890.

[7] Chuang, S. and Yang, C. 2014. Key success factors when implementing a green- manufacturing system. Prod. Plan. Control Manag. Oper. 25, 11, 923-937.

[8] Harzing, A. W. 2011. The publish or perish book: Your guide to effective and responsible citation analysis, 1 st ed. Melbourne, Australia: Tarma Software Research Pty Ltd.

[9] Setyaningsih, I., Indarti, N. and Jie, F. 2018. Bibliometric analysis of the term 'green manufacturing. Int. J. Manag. Concepts Philos. 11, 3, 315-339.

[10] Van Eck, N. J. and Waltman, L. 2010. Software survey: VOSviewer, a computer program for bibliometric mapping. Scientometrics. 84, 2, 523-538 